\title{
Alternativo
}

\section{PRECEITOS MORAIS: CONVERGÊNCIA DAS FILOSOFIAS RELIGIOSAS SANATA DHARMA E ESPIRITISMO}

Verioni Ribeiro Bastos (1)

Severino Celestino da Silva (2)

\section{Introdução}

A mais importante diferença entre o homem das sociedades arcaicas $e$ tradicionais, e o homem das sociedades modernas, com sua forte marca de judeu-cristianismo, encontra-se no fato de o primeiro sentir-se indissoluvelmente vinculado com o cosmo e os ritmos cósmicos, enquanto que o segundo insiste em vincular-se apenas com a historia. (ELIADE, 1992).

A religião, histórico e antropologicamente, foi alvo de diversas conceituações e a obrigação moral é campo para várias observações no agir do individuo. Não se deve pensar ter este estudo o objetivo de construir uma nova concepção religiosa, mas sim identificar nas concepções das religiões em foco a prática moral como elemento convergente dessas religiões.

Esse elemento convergente seria capaz de agregar práticas distintas e agir, potencialmente, para transformação de comportamentos em busca de justiça e harmonia no quadro macro-estrutural da sociedade.

Através de milênios de opressão das classes mais frágeis o conceito e a pratica dos preceitos morais foram deturpados e manipulados por interesses socioeconômicos e políticos o que levou a idéia, aparentemente perpétua, de ser a religião e suas práticas, originalmente, alienadoras e usurpadoras da liberdade de ação do individuo. De fato, na história se identifica o uso irrestrito das literaturas sagradas de vários povos para alienar e dominar, entretanto uma observação menos maniqueísta detecta que foi o uso indevido, destas escrituras, pela classe detentora do saber/poder, que levou o povo, desinformado, analfabeto e faminto, a aceitar e 
introjetar a prática religiosa de forma cega, não raciocinada e fanática gerando assim uma pseudo-consciência.

Seja pela exploração econômica e ou pelo desejo de manutenção do poder, a forma dogmática de apresentar a religião levou ao esquecimento prático dos preceitos morais, ao dogmatismo cientificista e a idéia de serem a "objetivação, exteriorização e interiorização" (BERGER, 2003, p.16) uma explicação plausível e suficiente para se compreender o processo homem/sociedade.

Assim, impediu e calou a possibilidade do uso desses mesmos preceitos para libertação e conscientização de ser o homem seu próprio “salvador” não dependendo de ritos, hierarquias e fórmulas. A prática dos preceitos morais pode ser elemento de união e força agregadora para desalienação legitimada do individuo, contrapondo-se a idéia niilista.

Os preceitos abordados: “dharma” (AMTRONG, 2002) e “ahimsa” (não violência) do Sanata Dharma ou, popularmente, conhecido como Hinduísmo e "Amai aos vossos inimigos” Caridade - presentes no Novo Testamento - e base da prática moral espírita são os preceitos inferidos para uma possível prática religiosa convergente. Desta forma não cabe aqui provar a veracidade do que escapa aos métodos racionais de ver o "real” ou satisfazer o ortodoxo modelo científico, fruto do modo pós-cartesiano de aferir os dados, mas de saber o que paira acima das questões dogmáticas dentro das religiões em foco, o liame de convergência e a possibilidade prática de no cotidiano do suject ter esta prática do dever moral ser tido como potencialidade para transformações sociais.

O conceito, a forma e a finalidade da prática moral ocupam o pensamento reflexivo desde a antiguidade. Dos sofistas, onde a moral tem suas bases nas convenções sociais, passando pelo pensamento socrático fundamentado na idéia que a moral encontra-se na própria natureza humana, seguindo até o pensamento religioso e ascético medieval onde a virtude para ser atingida precisa de um comportamento aniquilante do corpo e dos desejos presentes no ser humano.

No processo histórico, a moral transforma-se em objeto abordado pelas reflexões laicas fortalecendo assim a separação entre moral e religião, sendo aquela tida como reflexo das ações autônomas do homem determinado pela razão. Desta forma torna-se o pensamento kantiano um dos referenciais mais citados, posto este rejeitar a relatividade e basear-se na determinação da vontade para a realização do dever e para ser aplicado, também, as ações morais.

Segundo Chauí (2000), o que o ser humano racional deve valorizar como algo inquestionável é a dignidade dos seres humanos como pessoas. 
Essa visão kantiana conhecida como uma moral formalista, referencial da moral iluminista - visão homem-natureza/individuo-individuo -, é contestada por Hegel onde a moral é fruto da atividade do homem sobre o mundo (exteriorização) e conquista dessa atividade (objetivação). Hegel (2001) nos aponta que a consciência moral não pode renunciar a felicidade. Aquilo que seria tido como dever implicaria nessa consciência singular. Dessa forma, o autor sugere que a convicção individual e o saber sobre a mesma, constituem um momento objetivo no sentimento de dever cumprido.

Há também a defesa de o individuo não poder, na sua construção de mundo, atingir a prática da consciência moral ou da moralidade consciente e efetiva da forma transcendente ao que a sociedade e os indivíduos caracterizam como “dever cumprido”. Assim, complementa o autor,

A consciência moral enquanto essência negativa, para cujo dever puro, a sensibilidade tem apenas uma significação negativa... Pela consideração de que a moralidade consumada encerra uma contradição, se lesaria a santidade da essencialidade moral, e o dever absoluto pareceria como algo inefetivo. (HEGEL, 2001).

Essas afirmações demonstram a chave dicotômica sujeito-cultura/sujeito-história de onde se infere a tentativa de equilíbrio entre a vontade subjetiva individual e o objetivo cultural presente no pensamento hegeliano. Por outro ângulo o pensamento niilista moderno dá ênfase objetiva a respeito da moral como algo distante do interesse coletivo:

"O homem maduro, sábio diz: eu sou inteiramente corpo e nada, além disso, alma é apenas uma palavra para algo no corpo... Homens nobres e valentes que pensam assim são os mais afastados daquela moral que vê o característico da moral precisamente na compreensão e no cuidar dos outros ou no desinteresse”. (INCONTRI, 2004, p.36).

Esta afirmação é a mais patente no que diz respeito ao total comprimento do dever moral, com a associação imediata das relações entre os indivíduos e fruto de um processo histórico-educacional. A moral é um elemento de representação valorativa; no caso, valores aceitos culturalmente, como positivos e enobrecedores indicativos do bem proceder na perspectiva religiosa.

Já hoje, longe de haver algo pacífico em relação à moral, tem o discurso pós-moderno críticas ácidas às assertivas niilistas e socialistas, nos seus pontos fundamentais. 
"As velhas formas de honra e dignidade não morrem, são, antes, incorporadas ao mercado, ganham uma vida, enfim, como mercadorias. Com isso qualquer espécie de construção humana se torna permissível no instante em que se mostre economicamente viável”. (BERMAN, 2003, p.127).

Essa visão de Marshall Berman sobre a moral considera a fragilidade das relações no meio sócio-econômico e cultural, quando da sua experiência prática, unificando o caráter contraditório no processo histórico e não descartando a possibilidade de retomadas de padrões já em declínio ou totalmente rejeitados desde que estes figurem como elementos potencialmente úteis aos interesses vigentes.

Mesmo o discurso pós-moderno firmando-se no meio acadêmico através de seus referenciais, como Berman com criticas sobre os preceitos teóricos mais diversos e em todos os âmbitos, essa posição já sofre os efeitos das reações elaboradas por filósofos, sociólogos e pedagogos. Estes vêem na moral um veio de edificação da sociedade através do indivíduo consciente e ativo na sua participação social.

Em toda forma nadificante, que caracteriza o pós-moderno, há boa dose de rebelião a várias formas de verdade autoritárias e de arbitrariedade absoluta. A metafísica é crucificada em nome das imposições milenares das religiões; a objetividade cientifica é banida por conta de um dogmatismo cientificista herdado do positivismo; a visão histórica como construção evolutiva e com densidade teleológica fica esvaziada pelos excessos do hegelianismo ou pelo fracasso do marxismo aplicado, a verdade se dissolve em virtude das verdades ingenuamente absolutizadas $e$ culpa-se o próprio Deus pelas atrocidades humanas, e que por isso, é morto antologicamente, retirando o chão de todas as certezas, construídas na tradição ocidental... Se essa postura de rebelião pode ser historicamente compreensível, não se pode negar o caráter arbitrário de tal radicalismo. (INCONTRI, 2004, P.16).

Dessa forma observa-se ser o conceito e a prática dos preceitos morais, laicos e ou religiosos, alvos no processo histórico aonde foram fartamente analisados. Cada escola do pensamento filosófico, no decorrer dos séculos, desenvolveu uma linha de conduta influenciando seu tempo e meio cultural, estendendo-se até outras culturas, propiciando a dialética através de gerações.

Com a ação do homem sobre o mundo, com suas conquistas em vários âmbitos, mas sem perder a sua subjetividade, legitimando ou não as conclusões desses pensamentos, a 
moral, vem sendo, ainda hoje, alvo das inquietações do homem, seja por fazer parte do processo homem/natureza, seja pelo processo homem/cultura ou ambos associados no que, entretanto os estudiosos das relações com o extracorpóreo afirmam serem estas análises incompletas enquanto não levarem em consideração a prática dos preceitos morais, vistos como virtudes.

\section{Conceito de moral na Doutrina Espírita}

O caráter de revelação, efetuada fora dos ortodoxos padrões científicos modernos, não elimina o fato de ser o aspecto moral um dos pilares nas diretrizes desta religião. No Livro dos Espíritos a pergunta 629, segundo Allan Kardec, fora respondida pelos espíritos dos homens que deixaram o corpo físico, e define a moral:

A moral é a regra de bem proceder, isto é, de distinguir o bem do mal. Funda-se na observância da Lei de Deus. O homem procede bem quando tudo faz pelo bem de todos, porque então cumpre a Lei de Deus. (KARDEC. Q. 609).

Essa resposta é frontalmente contrária a visão de Nietzsche exposta no texto supra, pois aceita e estimula a idéia de ser preocupando-se com o outro e agindo sem interesses individuais onde mora a possibilidade de justiça material e extracorpórea.

Ainda, no Livro dos Espíritos, a Doutrina Espírita afirma, categoricamente, ser o "mal moral” fruto das ações dos homens que são livres para escolher e que o homem, seja individualmente ou homem ser social, só aprende através das experiências posto ser assim a forma de conhecer e apreender o que são o bem e o mal nas suas conseqüências:

Já vos dissemos: os Espíritos foram criados simples e ignorantes. Deixa Deus o homem a escolha da senda. Tanto pior para quem toma o mau caminho; sua peregrinação será mais longa. Se não houvesse montanhas não poderia o homem compreender que se pode subir e descer... É necessário que o Espírito adquira a experiência e, por tanto, precisa conhecer o bem e o mal. É por isso que existe união entre o espírito e o corpo. (KARDEC. Q. 639). 
É evidente a idéia do homem em processo com bases no desenvolvimento intelectual e moral, pois é desta foram que o individuo desenvolve sua inteligência e aprimora suas virtudes potenciais e ser aonde livre arbítrio lhe dá a responsabilidade de suas escolhas e ações. Aqui se encontra semelhança com o pensamento kantiano onde a ação da vontade é essencial para realização do dever moral ou negá-lo e com o de Hegel, pois ao escolher está agindo sobre o mundo (exteriorização) e independente de ser uma ação negativa ou positiva sua conquista é a objetivação - sua ação sobre o mundo sofrendo as reações dessas ações.

A Doutrina Espírita, considerando essas explicações reveladas, aborda na sua conceituação de sociedade,

... os dois planos de vida: o espiritual, ou dos espíritos, e o físico, ou dos homens. Reúne, assim, em uma mesma coletividade todos os seres espirituais que gravitam (ou habitam) em torno do nosso planeta nos dois níveis de existência, (LOBO, 1991, P.35).

E ainda,

A humanidade é um ser coletivo em quem se operam as mesmas revoluções morais por que passa todo ser individual. (KARDEC. GN. 18, 12).

A idéia é de que tudo acontecido de individuo para individuo não se circunscreve a esses dois, mais atingi toda a humanidade: física ou extra-física. Assim, o progresso moral guia, segundo o Espiritualismo Moderno, as escolhas dos indivíduos, que apreende e compreende o que são o bem e o mal nas suas conseqüências.

A moral na Doutrina Espírita resume-se na caridade e na humildade, independente de credo, igreja ou da própria religião em seu âmbito institucional. É a renovação moral do homem que proporcionará o progresso geral da humanidade, que a libertará e a levará à paz porque a justiça será praticada. Segundo Ney Lobo em O Plano Social de Deus, as classes sociais seguem a Doutrina Espírita e isso se apresenta na assimilação moral educativa sistemática. É uma função sócio-espiritual, isso se apresenta na medida em que valores morais são difundidos, por indivíduos missionários, dentro da sociedade dirigida, principalmente, para aqueles que ainda não se renovaram moralmente.

Na perspectiva de Ney Lobo são descritas as 
atitudes subjetivas para assimilação moral" que são conseqüência da determinada função sócio-espiritual, dos quais foram citados alguns exemplos, nominalmente. Essa influenciação forma "o reconhecimento de reais valores intelectuais e morais... a admiração gerada por aquele reconhecimento... esforço de imitação - que não é copia nem subserviência, mas no sentido sociológico -... internalização de alguns daqueles valores... Essa assimilação viabiliza-se no íntimo de cada um... (LOBO, 1991, P.120).

Assim é exposto por se tratar de uma perspectiva em busca da compreensão das coisas e idéias para realização sobre o meio a partir do individuo (exteriorização) e conquista do mundo através dessas atividades como preconizam o pensamento hegeliano.

\section{O Sanata Dharma}

O Ocidente tem uma compreensão do pensamento filosófico indiano ainda pequeno, quando não limitado pelos preconceitos eurocêntricos, por este ainda não ser perscrutado com um olhar mais abrangente. A própria determinação de Hinduísmo para a religião do povo indiano é um equivoco histórico e lingüístico, fruto das conclusões e adaptações colonizadoras como bem expõe Zimmer e ainda traz sua visão do potencial dessa cultura e seus objetivos focados para o ser humano e não só para seu povo e seus interesses geopolíticos.

Os filósofos hindus, como os do Ocidente, discorrem acerca de valores éticos e critérios morais. Estudam, também, os traços visíveis da existência fenomênica, criticando os dados da experiência externa e obtendo conclusões sobre os princípios que serviram de base... mas a preocupação fundamental foi sempre a transformação, e não a informação; uma mudança radical da natureza humana e, com isto, uma renovação na sua compreensão não só de mundo exterior, mas também de sua própria existência; uma transformação tão completa quanto possível que, ao ser coroada pelo êxito, leva a uma total conversão ou renascimento, (ZIMMER, 2003, P.21).

É essa idéia de transformação geral do mundo e do ser humano, considerada como objetivo dos seguidores das práticas e filosofias abrigadas sob o nome de Sanata Dharma. Para essa transformação substancial essas filosofias foram forjadas nos costumes, nos "mitos”, tradições orais e várias práticas espiritualistas com suas bases morais dando um caráter específico ao tratamento com a espiritualidade e esta em relação ao indivíduo. 
O conjunto dessas visões derivou escolas filosóficas com o objetivo de procurar atingir o vedanta védico - verdade - através do siddhanta - Conclusão última - e tem o dharma como base moral para sua vida. Denominado pelos filósofos, estudiosos e o povo indiano como Sanata Dharma. Segundo lembra Dasa Goswami (2002, p.88) o pesquisador Ainslee T. Embree já fez referencia que as palavras hindu e hinduísmo não são védicas.

... Índia é uma palavra que os gregos tomaram emprestado dos persas, que, por causa da dificuldade que tinham com o 's' inicial, chamavam o grande rio Sindhu de 'Hindu'. Foi com essa palavra que os estrangeiros passaram a designar a religião e a cultura dos povos que viviam na terra banhada pelos dois rios, o Indo e o Ganges, embora próprios nativos não usassem o termo. (GOSWAMI, 2002, P.88)

Esse pensamento colonizador é generalizante e emprega ao todo da vida sócio-cultural e espiritual da Índia, disseminou a idéia de um povo inculto e ignorante gerando uma serie de barreiras impeditivas para apreender e assimilar o vasto leque desse conhecimento em seus vários âmbitos.

As escolas mais conhecidas e abalizadas por serem ortodoxas e seguirem os Vedas são a Advaita-vedanta (não dualista) com o ãcãrya Sankara, divulgador do monismo impessoal e afirma serem as jivas - almas eternamente fragmentárias - idênticas a Deus; uma outra Escola é a de Ramanuja referencial para o Vaisnavismo (adoração a Visnu, ou Bhagavan que divulga o vasistadvaita: é o não-dualismo qualificado, ou seja, faz diferença entre o Brahman Supremo e a jivas, também opositor contumaz de Sankara e seu monismo impessoal. Existem, ainda, mais duas escolas: a do ãcãrya Madhva - com a divulgação do suddha-dvaita (dualismo puro) que prega a total diferenciação entre Brahman e as jivas - e ãcãrya Caitanya, mais recente de todas as escolas oriunda do Séc. XVI, na Bengala, ele desenvolveu a corrente de acintya-bhedabheda-ttatva que é o teísmo puro onde Brahman é dual e não dual que este e as jivas são inconcebíveis e simultaneamente iguais e diferentes.

Todas essas escolas podem ser englobadas pelo Sanata Dharma e procuram seguir as escrituras nos seus preceitos védicos originais. As sãstras ou escrituras védicas,

... compreendem um todo harmonioso com uma conclusão harmoniosa (siddhanta). Logo podemos aceitar como literatura védica fidedigna qualquer obra que, apoiando-se no siddhanta védico, não lhe deturpa o sentido, mesmo que o trabalho não seja uma das escrituras originais. (GOSWAMI, 2002, p.12) 
Vê-se nessa afirmação a idéia inerente da potencial convergência dos ensinamentos de diferentes doutrinas posto a verdade última (vedante) ser a busca dos seguidores da literatura védica e essa verdade última independer de credos, religiões ou qualquer doutrina nos seus aspectos institucionais, mas sim depender de serem os ensinamentos intrínsecos a filosofia moral e sua finalidade comum, ou seja, é a busca do melhoramento completo do homem nos seus diversos âmbitos para sua liberdade plena desde que aqui, no plano terreno ou mãya, e não só depois do desenlace de corpo físico.

\section{A moral nas escrituras Vedas - Sanata Dharma}

Dharma: palavra muito utilizada para a moralidade. Os ensinamentos védicos ensinam os princípios morais ideais, entretanto reconhece e compreende a atual condição humana. É a natureza interior de cada individuo com seu nível individual de desenvolvimento. Assim o Dharma ou dever moral é algo intrínseco ao se ser humano expressado nos pensamentos, nas palavras e nos atos, no caso nos lilás de Khrisna,

Que o filho de Pandu, possuidor de inteligência, autodomínio, brahamacharya. Misericórdia, justiça, energia e vigor espiritual, faça as suas perguntas a mim... que o filho de Pandu, em quem se encontra a verdade e a caridade e as penitencias, o heroísmo, a calma, a inteligência e o destemor faça suas perguntas a mim. (BESSANT, s/d).

São essas qualidades que o Dharma possui ou para elas conduz o individuo. Considerando aqui a natureza condicionada do ser humano, o bem e o mal não são absolutizados, cada indivíduo tem o seu Dharma, o seu dever moral.

Cada sujeito possui diferentes deveres sendo possível esta observação através da exteriorização dos seus pensamentos e ações, pois os aspectos essenciais da vida são os mesmos para todos os indivíduos, contudo a evolução e desenvolvimento em cada momento da existência é um processo singular e individual. Isso implica a idéia de ser o Dharma, também “... a lei que governa o seu estágio seguinte de desenvolvimento”. (BESSAN T, s/d).

Essa lei impele ao individuo a busca do autoconhecimento posto ser esse o passo fundamental para melhorar a sua condição humana o que contribuirá para o todo universal da humanidade. "Pensamos por diferenças, sentimos por diferenças, e conhecemos por 
diferenças. É somente por meio das diferenças que nos sabemos homens vivos e pensantes.” (BESSAN T, s/d).

O ser humano, segundo a literatura védica, ainda não compreende a essência do aspecto espiritual - Sat ou Ishvara -, então precisa ainda pensar dentro dos limites do condicionado e do separado - asat ou maya - É necessária a compreensão do pôr que das diferenças. Há toda uma organização social dentro da literatura védica orientada pela distinção e aplicação do dharma aos membros da sociedade. Essa distinção no seu aspecto védico puro não leva em consideração os aspectos partidários ou de posição social.

O Dharma aplica-se as condições naturais presentes no individuo em toda civilização humana, não é algo tido como aplicado, exclusivamente, ao povo hindu ou a seus praticantes. As varnas - ordens sociais a que compete o Dharma específico - são, cada uma com suas atribuições definidas da seguinte forma: Brahamanas (intelectuais); os Ksatryas (administradores e guerreiros); os vaisyas (agricultura comerciante); e os sudras (artesão).

Essas varnas foram, por interesses econômicos, associados à idéia de hereditariedade, ou seja, bastaria que o indivíduo nascesse em determinada casta e teria, por isso, as características e atribuições imbuídas daquele Dharma. Essa divisão foi e até hoje é deturpada por interesses das classes econômicas e sua ordem social vigente implantada no processo histórico que levou a uma profunda influenciação da Índia pelo Ocidentalismo capitalista, mas segundo Dasa Goswami essas divisões de castas e ordens sociais só podem ser interligadas com as varnas e seus Dharmas quando atingem o fim nele inerente: “Satisfazer o Senhor Hari”.

É através da evolução paulatina e continua que se adquiri o Dharma específico a cada momento espiritual em que se encontra o indivíduo. Só através do Siddhanta, que é o reitor da literatura e da tradição védica, é que pode ser cumprido todo o Dharma. Cumprido este, atingir a moksa - liberação - é o próximo passo para o seguidor dos Vedas e assim a plena redenção no Bhagavan Supremo.

A moral sendo complexa na sua apreensão e aplicabilidade, segundo Annie Besant, nas escrituras védicas encontra-se a recomendação “de se estudar do ponto de vista de quem vai praticá-la. Ao se decidir o que é bom ou mal para um determinado individuo, deve-se levar em conta o estagio de crescimento alcançado pelo individuo”. (BESSAN T, s/d).

Essa observação refere-se não só aos indivíduos, mas as populações e suas escolas. Acredita o conhecimento védico não ser ele localizado e restrito a determinadas escolas e religiões aplicadas a estudar e ensinar os preceitos morais. Mas, também, acreditam seus filósofos e estudiosos que esse conhecimento é indispensável ao progresso da humanidade, 
entretanto é preciso o bom senso para o um ensino prático e teórico e não degenerar em teorias inatingíveis.

Quando um mandamento apropriado a um semi-selvagem é declarado, universalmente, obrigatório não obstante provir ele da mesma origem que o mandamento destinado ao santo e dirigir-se aos mesmos homens, insinua-se então um sentimento de irrealidade do qual resulta a confusão de idéias. (BESSAN T, s/d).

Dessa forma o Dharma é constituído de princípios religiosos e funcionam como preceitos morais preconizando serem estes ideais já que possuem a capacidade de conduzir o ser humano a atingir a libertação das ilusões materiais - maya -.

\section{Conclusão}

Em um contexto geral a idéia de serem as religiões distintas e etnocêntricas é aceita quase incontestavelmente pelo meio acadêmico, principalmente quando são meios culturais singulares como os continentes Ocidental e Oriental, entretanto o aprofundamento nestas práticas religiosas demonstra que há aspectos filosóficos e morais convergentes em suas práticas.

O Sanata Dharma e o Espiritismo em suas práticas externas são, em uma abordagem superficial e estereotipada, totalmente diferentes e como em todo o processo histórico houve inclusão e exclusão de algumas fórmulas durante esse processo, embora se tenha mantido os fundamentos, de acordo com seus adeptos, imutáveis e pertencentes à verdade última. Ambas vêem na moral uma veio de edificação da sociedade através do indivíduo consciente e ativo na sua participação social, principalmente porque, segundo eles possuem e compreendem a relação direta com o plano extracorpóreo.

A moral na Doutrina Espírita resume-se na caridade e na humildade, independe de credo, igreja ou religião assim sendo é a renovação moral do homem que proporcionará o progresso geral da humanidade, que a libertará e a levará para paz porque a justiça será praticada. O progresso moral guia, segundo o Espiritualismo Moderno, as escolhas dos indivíduos.

Pode-se concluir, com a observação presencial realizada nos Lares Espíritas, ser o dever moral o objetivo em sua prática. Não é algo fundado na exteriorização, mas e, 
principalmente, na transformação íntima apreendendo e compreendendo o que são o bem e o mal nas suas conseqüências ao assumirem total responsabilidade pelas escolhas e atos dentro do seu nível evolutivo.

O Dharma - moralidade - é, também, busca da realização do dever para atingir a liberdade. Observado isso em reuniões de membros da Sociedade Internacional para a Consciência de Krishna - ISKCON - conclui-se que seus adeptos buscam na denominada conclusão harmoniosa a compreensão da verdade última - vedanta. Por isso considera não só as suas próprias escrituras como verdade, mas qualquer ensinamento baseado nessa verdade siddhanta -, com objetivo de trabalhar em favor do semelhante e conseqüentemente da sociedade como um todo.

Desse modo as duas religiões, mesmo diante de suas abordagens diferenciadas sobre alguns pontos filosóficos e práticos, têm laços comuns e convergentes por possuírem o mesmo objetivo como se observa no texto supracitado, embora adeptos dessas práticas não se aprofundem e adotem um fanatismo por aferrarem-se aos aspectos exteriorizados, que segundo Geridhari Das e Allan Kardec não são essenciais para a prática do dever moral, quando não se voltarem exclusivamente para o lado místico e tudo isso advertido nos próprios ensinamentos contidos nas obras básicas de suas religiões.

Assim ambas as filosofias aceitam a idéia de um projeto Superior advindo de um Organizador eterno e impenetrável a não ser pelos seus atributos/atrativos, também a idéia de sermos infinitos e o plano material apenas ser elemento transitório para nossa aprendizagem onde devemos conquistá-lo para nos libertar. Para ambas o ser extracorpóreo - espírito/jivas sobrevive à decomposição do corpo físico e vai habitar outros mundos/planos buscando sua libertação/moksa.

Apresentar provas desses preceitos não é o alvo e não há preocupação alguma em respeitar ou difundir qualquer dogma gerador de disputas. Importa-nos é o laço doutrinário comum da prática moral. Observa-se que ambas podem usar tais práticas na transformação para atingir a liberdade ainda no corpo físico. Podem-se apresentar dois preceitos dentro do conjunto pertencentes a essas duas filosofias: Ahimsa - não prejudicar o inocente - e Amai vossos inimigos - não ferir quem quer que seja -, assim é preceituada a não violência e tudo que prejudique o outro é tido como ignorância.

Assim, contrariando Nietzsche e seu conceito de que ser sábio é considerar a moral como algo dissociado da compreensão e do desinteresse aplicados em favor dos outros; infere-se a hipótese de ser a prática dos preceitos morais, com conotações religiosas, algo 
construtivo e capaz de agir como elemento de mudança de padrões de relacionamento entre os indivíduos e conseqüentemente atingir o quadro macro estrutural da sociedade.

\section{Referências:}

ALLAN, Kardec. O Livro dos Espíritos. Item 609. São Paulo, Editora Formar Ltda.

ALLAN, Kardec. Gênese. Q - XVIII, 12 - Revisada e Organizada por Ubiratan Rosa - São Paulo, Editora Formar Ltda.

AMSTRONG, Kerem. Uma Historia de Deus. 6º Ed. Companhia da Letras: São Paulo, 2002.

BERMAN, Marshall. Tudo que é sólido se desmancha no ar. São Paulo, $19^{\circ}$ Edição. Companhia da Letras, 2003.

BESANT, Annei. Dharma. s/ed. Pensamento. São Paulo.

CHAUÍ, Marilena. Convite a Filosofia. Ática: São Paulo, 2000.

ELIADE, Mircea. O mito do eterno retorno. $9^{\circ}$ Ed. São Paulo: Mercuryo, 1992.

GOSWAMI, Satsvarupa Dasa. Introdução A Filosofia Védica. Brasília, $2^{\circ}$ Edição. Bhaktivedanta Book Trust, 2002.

HEGEL. Fenomenologia do Espírito II. $2^{\circ}$ Edição Vozes, 1993.

INCONTRI, Dora. Pedagogia Espírita.1 Edição. Editora Commenius, 2004 - p.16.

LOBO, Ney. Filosofia Social Espírita. $2^{\circ}$ Edição. FEB, 1991.

MEAD, G. H. in BERGER, Peter. O Dorssel Sagrado: Elementos para uma teoria sociológica da religião. São Paulo: Paulos. $4^{\circ}$ Edição, 2003.

NIETZSCHE in INCONTRI, Dora. Pedagogia Espírita. $1^{\circ}$ Edição. Editora Commenius, 2004.

ZIMMER, Heinrich. Filosofia da Índia. São Paulo, $2^{\circ}$ Edição Revisada. Editora Palas Athena, 2003;

(1) Verioni Ribeiro Bastos é Historiadora e Mestranda em Ciências das Religiões pela Universidade Federal da Paraíba - UFPB. E-mail: verionivrb2@hotmail.com;

( 2) Severino Celestino da Silva é Docente no Mestrado em Ciências das Religiões na Universidade Federal da Paraíba - UFPB. 